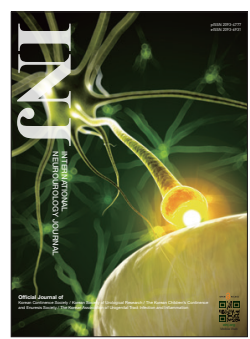

\title{
The Far-Reaching Effects of Neuroinflammation
}

\author{
Jin Wook Kim (id https://orcid.org/0000-0003-4157-9365 \\ Department of Urology, Chung-Ang University College of Medicine, Seoul, Korea \\ E-mail: jinwook@cau.ac.kr
}

A patient with a neurological ailment is faced with a wide spectrum of symptoms, through hidden and unclear paths that spark from the most closed-off of spaces in the body, the effects that begun from the brain inevitably finds its way affecting various organs. The pathophysiology of the nervous system affecting the urological system is not novel in itself. Urologists have always had to consider the changes become upon the bladder with regards to the nervous system. But there the understanding has always ended. Here, we see a glimpse of the damage done "up there." Not in complex neurological errors, but in the role of something we are more familiar with, inflammation.

Through a series of reviews, the supplementary issue introduces the readers to inflammatory changes in brain that may explain the pathophysiologic origins of familiar diseases. We see how neuroinflammation alters Alzheimer disease [1,2], and depression [3]. In "Exercise and Neuroinflammation in Health and Disease," exercise, which clinicians have always recommended as a colloquial prescription for almost everything, has a specific role in combating neuroinflammation [4].

An exciting new article by Jeong et al. [5] describes the effect of the unfortunately all too familiar postoperative cognitive dysfunction and a potential treatment with polydeoxyribonucleotides, while Kim et al. [6] shows hyperlipidemia related memory impairment, and how to combat it with Berberine.

The mission statement of the INJ has been to create a common ground, a place where the neurologist may converse with the urologist, where the scientist can convey her ideas to the cli- nician. Through the language of inflammation, we hope the readers will be able to approach these neurological maladies with more familiarity and confidence, understanding the farreaching hand of the nervous system, and how it may closely affect the bladder.

- Conflict of Interest: No potential conflict of interest relevant to this article was reported.

\section{REFERENCES}

1. Yang SH. Cellular and molecular mediators of neuroinflammation in Alzheimer disease. Int Neurourol J 2019;23(Suppl 2):S54-62.

2. Kim B, Choi Y, Kim HS, Im HI. Methyl-CpG binding protein 2 in Alzheimer dementia. Int Neurourol J 2019;23(Suppl 2):S72-81.

3. Maeng SH, Hong H. Inflammation as the potential basis in depression. Int Neurourol J 2019;23(Suppl 2):S63-71.

4. Seo DY, Heo JW, Ko JR, Kwak HB. Exercise and neuroinflammation in health and disease. Int Neurourol J 2019;23(Suppl 2):S82-92.

5. Jeong H, Chung JY, Ko IG, Kim SH, Jin JJ, Hwang L, et al. Effect of polydeoxyribonucleotide on lipopolysaccharide and sevofluraneinduced postoperative cognitive dysfunction in human neuronal SH-SY5Y cells. Int Neurourol J 2019;23(Suppl 2):S93-101.

6. Kim M, Kim TW, Kim CJ, Shin MS, Hong M, Park HS, et al. Berberine ameliorates brain inflammation in poloxamer 407-induced hyperlipidemic rats. Int Neurourol J 2019;23(Suppl 2):S102-10. 